\title{
Multi-annual droughts in the English Lowlands: a review of their characteristics and climate drivers in the winter half year
}

\author{
C. K. Folland et al.
}

Correspondence to: J. Hannaford (jaha@ceh.ac.uk) 


\section{Supplementary Information S1}

Figure S1 shows the mean global PMSL anomalies for 1901-2010 from the Twentieth Century Reanalysis for each calendar month of the winter half-year followed by the rainfall anomalies over Europe. The order of the PMSL or rainfall diagrams are: October and November (top row), December and January (second row) and February and March (third row). In all months rainfall anomalies over the English Lowlands are negatively correlated with local PMSL anomalies, though the former are very weak in October and January. Only January is marginally wet. The diagrams show how English Lowland climate anomalies in each month during La Niña are part of quasi-global scale atmospheric circulation anomalies, and coherent rainfall patterns over Europe.

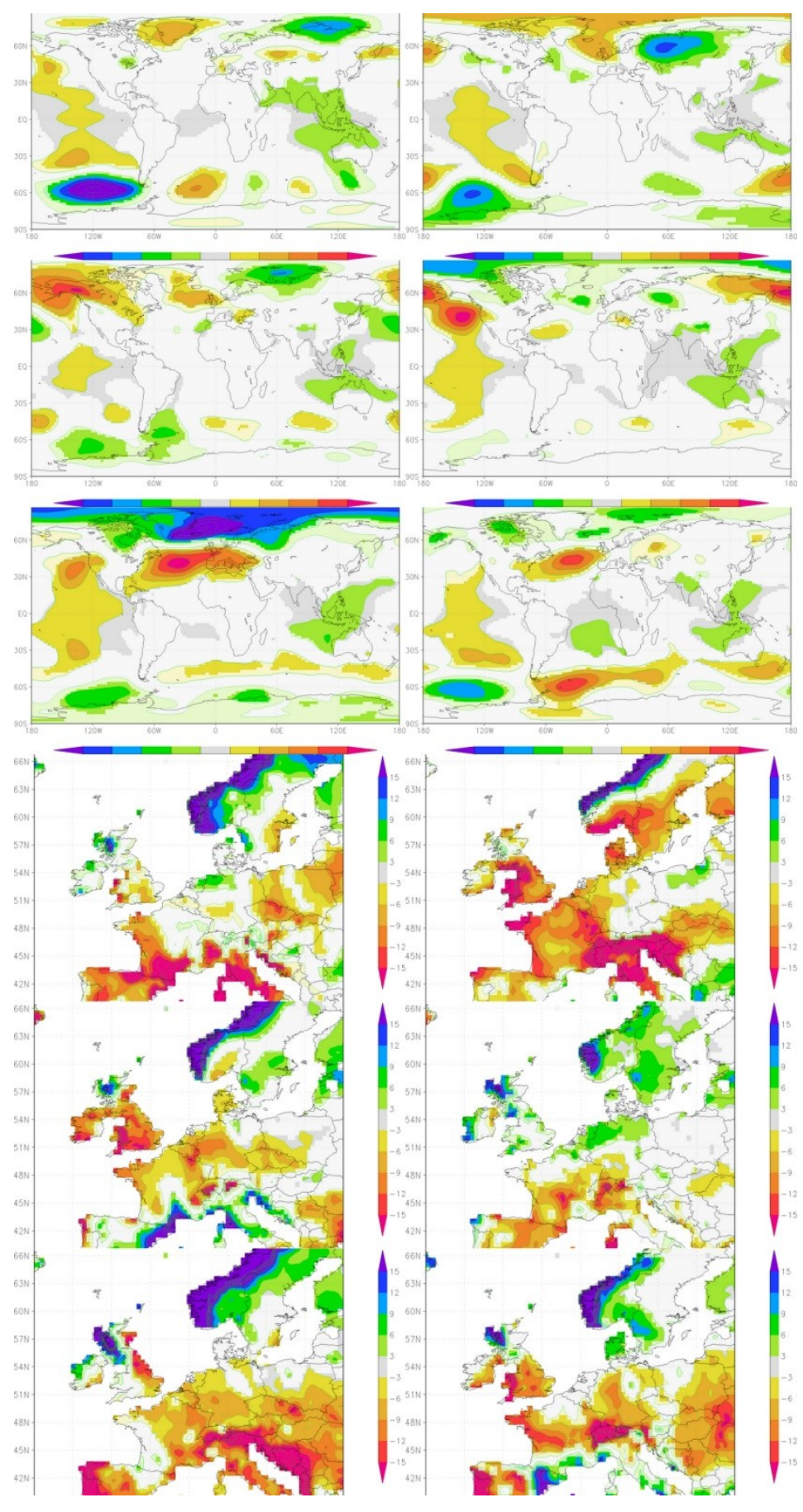

